\title{
Noncanonical Effects of Oral Thrombin and Factor Xa Inhibitors in Platelet Activation and Arterial Thrombosis
}

\author{
Amin Polzin ${ }^{1, *}$ Lisa Dannenberg ${ }^{1, *}$ Manuela Thienel ${ }^{2,3}$ Martin Orban ${ }^{2,3}$ Georg Wolff ${ }^{1}$ \\ Thomas Hohlfeld ${ }^{4}$ Tobias Zeus $^{1}$ Malte Kelm ${ }^{1}$ Tobias Petzold 2,3 (1)
}

\author{
${ }^{1}$ Department of Cardiology, Pulmonology, and Vascular Medicine, \\ Cardiovascular Research Institute Düsseldorf, Medical Faculty of the \\ Heinrich Heine University Düsseldorf, Düsseldorf, Germany \\ ${ }^{2}$ Department of Cardiology, LMU München, Munich, Germany \\ ${ }^{3}$ DZHK (German Centre for Cardiovascular Research), Munich Heart \\ Alliance, Munich, Germany \\ ${ }^{4}$ Instituton of Pharmacology and Clinical Pharmacology, Heinrich \\ Heine University Düsseldorf, Düsseldorf, Germany
}

Address for correspondence Tobias Petzold, MD, Medizinische Klinik und Poliklinik I, Klinikum der Universität München, Marchioninistraße 15, D-81377 Munich, Germany

(e-mail: tobias.petzold@med.uni-muenchen.de).

\author{
Abstract \\ Keywords \\ - anticoagulation \\ - anticoagulants \\ - myocardial infarction \\ - platelet aggregation
}

Nonvitamin K oral anticoagulants (NOACs) or direct oral anticoagulants comprise inhibitors of factor Xa (rivaroxaban, apixaban, edoxaban) or factor lla (dabigatran). Both classes efficiently interfere with the final or penultimate step of the coagulation cascade and showed superior net clinical benefit compared with vitamin $\mathrm{K}$ antagonists for prevention of thromboembolic events in patients with AF and for prevention and therapy of deep vein thrombosis and pulmonary embolism. None the less, accumulating data suggested, that there may be differences regarding the frequency of atherothrombotic cardiovascular events between NOACs. Thus, the optimal individualized NOAC for each patient remains a matter of debate. Against this background, some basic and translational analyses emphasized NOAC effects that impact on platelet activity and arterial thrombus formation beyond inhibition of plasmatic coagulation. In this review, we will provide an overview of the available clinical and translational evidence for so-called noncanonical NOAC effects on platelet activation and arterial thrombosis.

\section{Introduction}

In patients with atrial fibrillation (AF), guidelines recommend nonvitamin $\mathrm{K}$ oral anticoagulants (NOACs) over vitamin $\mathrm{K}$ antagonists (VKAs) for prevention of thromboembolic complications. ${ }^{1}$ Furthermore, NOAC has become the anticoagulant of choice for the treatment of venous thromboembolic events. ${ }^{2}$

In particular, patients with AF are on high risk for atherothrombotic events due to the presence of coronary artery

Both authors contributed equally.

diseases (CADs) and the optimal NOAC for each patient remains a matter of debate. To date, inhibitors of factor Xa (FXa) (rivaroxaban, apixaban, edoxaban) or FIla (dabigatran) are available. All of them were shown to have a superior net clinical benefit as compared with VKA. ${ }^{3-8}$ However, landmark trials showed differences regarding the frequency of atherothrombotic, ischemic events between NOACs. For the oral thrombin inhibitor dabigatran, but also for ximelagatran (active metabolite: melagatran), whose approval was withdrawn due to hepatotoxicity, clinical randomized studies revealed an increased risk of myocardial infarction (MI)

(c) 2020. Thieme. All rights reserved. Georg Thieme Verlag KG,

Rüdigerstraße 14,

70469 Stuttgart, Germany
DOI https://doi.org/ 10.1055/s-0040-1716750. ISSN 0340-6245. accepted after revision

August 1, 2020

published online

September 17, 2020 


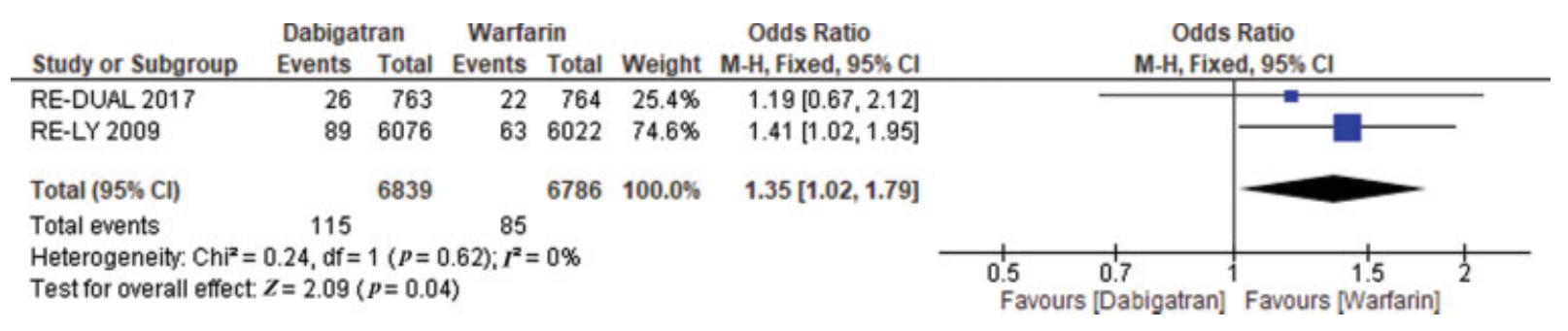

Fig. 1 Meta-analysis of risk of myocardial infarction under oral factor Ila (FIla) inhibition. Individual and summary odds ratios with 95\% confidence intervals for myocardial infarction in studies comparing Flla inhibition to vitamin K antagonist (VKA) treatment in patients with atrial fibrillation. M-H, Mantel-Haenszel estimate; $I^{2}$ describes heterogeneity among studies; fixed, fixed-effects model.

(-Fig. 1) in patients. ${ }^{5,9,10}$ In contrast, FXa inhibition by rivaroxaban and apixaban showed a numerical decrease in MI rates (- Fig. 2) compared with VKA. 3,4,6,11,12

This was surprising and unexpected. Additionally, it seems counterintuitive given that all NOACs target either the penultimate or final step within the coagulation cascade. In contrast to such canonical effects that ultimately interfere with thrombin-induced platelet activation and coagulationrelated events, this review focuses on "noncanonical" NOAC effects occurring during primary and secondary hemostasis, but independently of catalytic active thrombin.

Thrombin formation results from the sequential activation of an ensemble of serine proteases. Depending on the nature of coagulation trigger, the extrinsic or intrinsic coagulation pathway is initiated. Both are finally capable of activating FX to FXa. Catalytic active FXa cleaves FII (prothrombin) to FIla (thrombin) which in turn processes FI cleavage (fibrinogen) and fibrin formation. In the context of atherothrombosis, thrombin takes a central role in mediating various effects which were recently reviewed. ${ }^{13}$ Being formed within seconds at sites of atherosclerotic plaque rupture, thrombin is the key multiplier of a locally forming prothrombotic milieu. Its antithrombotic effects, for example, by activation of protein $C$, are negligible in the acute setting. Given the plethora of parallel occurring interwoven thrombin-mediated effects at site of injury, two key functions that mediate thrombin's prothrombotic activity have to be highlighted. First, as mentioned before, thrombin cleaves fibrinogen into fibrin, thereby contributing to the stabilization of the forming clot. Second, thrombin acts as a potent inducer of platelet activation, aggregation, and reactivity, ${ }^{14,15}$ which is associated with an increased risk of MI. ${ }^{16,17}$ Mechanistically, thrombin triggers platelet activation either through proteolytic activation of protease-activated receptor (i.e., PAR-1, PAR-4) or through binding to glycoprotein (GP) Ib $\alpha$ the most abundantly expressed platelet thrombin receptor. ${ }^{18}$ of note, the latter mechanism is less potent compared with PAR-induced signaling.

In addition to their serial occurring actions within the coagulation cascade, thrombin and FXa exhibits various pleiotropic effects ${ }^{19,20}$ which are reviewed elsewhere and are beyond the scope of this review.

Given the high substrate specificity and binding affinity of NOACs, it is tempting to speculate that the clinically observed differences of ischemic events were due to so far unknown, coagulation independent and thus noncanonical NOAC effects on platelet function and platelet-driven arterial thrombosis. At sights of atherosclerotic plaque rupture, platelets become immediately recruited as first responders and contribute by different mechanism to deleterious thrombus formation. ${ }^{21}$ Against this background and the insufficiently understood role of NOACs in the context of platelet activation and arterial thrombosis, several in vitro and in vivo animal studies were initiated.

\section{Oral Thrombin Inhibitors}

Since RE-LY, the oral thrombin inhibitor dabigatran (dabigatran etexilate) is known to sufficiently prevent stroke in patients with AF. However, a debate if it enhances risk of MI emerged as the MI rate was higher in dabigatran-treated patients as compared with VKA in RE-LY for both dose regimens (110 and $150 \mathrm{mg}$ twice daily). ${ }^{5}$ A repeated analysis

\begin{tabular}{|c|c|c|c|c|c|c|c|c|c|c|}
\hline \multirow[b]{2}{*}{ Study or Subgroup } & \multicolumn{2}{|c|}{ NOAC } & \multicolumn{2}{|c|}{ VKA } & \multicolumn{3}{|c|}{ Odds Ratio } & \multirow{2}{*}{\multicolumn{2}{|c|}{$\begin{array}{c}\text { Odds Ratio } \\
\text { M-H, Fixed, } 95 \% \mathrm{Cl}\end{array}$}} & \\
\hline & Events & Total & Events & Total & Weight & M-H, Fixed, 95\% Cl & & & & \\
\hline ARISTOTLE 2011 & 90 & 9120 & 102 & 9180 & $20.8 \%$ & $0.89[0.67,1.18]$ & & & & \\
\hline AUGUSTUS 2019 & 72 & 2306 & 80 & 2308 & $16.0 \%$ & $0.90[0.65,1.24]$ & & & & \\
\hline ENGAGE AF TIMI 48 & 133 & 7035 & 141 & 7036 & $28.6 \%$ & $0.94[0.74,1.20]$ & & & & \\
\hline ENTRUST 2019 & 29 & 751 & 23 & 755 & $4.6 \%$ & $1.28[0.73,2.23]$ & & & & \\
\hline Pioneer AF PCl 2016 & 19 & 709 & 21 & 706 & $4.2 \%$ & $0.90[0.48,1.69]$ & & & & \\
\hline ROCKET AF 2011 & 101 & 7131 & 126 & 7133 & $25.7 \%$ & $0.80[0.61,1.04]$ & & $=$ & t & \\
\hline Total $(95 \% \mathrm{Cl})$ & & 27052 & & 27118 & $100.0 \%$ & $0.90[0.79,1.02]$ & & & & \\
\hline Total events & 444 & & 493 & & & & & & & \\
\hline $\begin{array}{l}\text { Heterogeneity: } \mathrm{Chi}^{2}= \\
\text { Test for overall effect: }\end{array}$ & $\begin{array}{l}46, \mathrm{df}=5 \\
=1.59(p\end{array}$ & $\begin{array}{l}(p=0.7 \\
=0.11)\end{array}$ & $8) ; 1^{2}=0$ & & & & 0.5 & $\begin{array}{c}0.7 \\
\text { Favours NOAC }\end{array}$ & 1 Favours VKA & $\frac{1}{2}$ \\
\hline
\end{tabular}

Fig. 2 Meta-analysis of risk of myocardial infarction under oral factor Xa (FXa) inhibition. Individual and summary odds ratios with 95\% confidence intervals for myocardial infarction in studies comparing FXa inhibition to vitamin $\mathrm{K}$ antagonist (VKA) treatment in patients with atrial fibrillation. M-H, Mantel-Haenszel estimate; $I^{2}$ describes heterogeneity among studies; fixed, fixed-effects model. 
of RE-LY requested by the Food and Drug Administration revealed four hitherto unreported MIs and added 28 silent MI events. ${ }^{22,23}$ Adding these data, the difference in MI rate was not statistically significant anymore. Moreover, a metaanalysis of 11 randomized controlled trials (RCTs) comparing dabigatran to VKA recently revealed a $41 \%$ higher risk of MI in dabigatran-treated patients as compared with VKA. ${ }^{10}$ Another landmark study investigated dabigatran in a population with pre-existing CAD and thus an enhanced MI risk. RE-DUAL investigated dabigatran (110 or $150 \mathrm{mg}$ ) and P2Y12-inhibition in comparison to triple therapy with VKA, aspirin, and P2Y12-inhibition in AF patients who undergo percutaneous coronary interventions $(\mathrm{PCIs}) .^{9}$ As expected, patients receiving dual therapy with dabigatran (110 and $150 \mathrm{mg}$ ) had fewer bleeding events. However, again a numerical increase toward higher MI rate was observed. Especially in patients treated with $110 \mathrm{mg}$ twice daily. This was interesting, as sample size was substantially smaller (REDUAL PCI: 2,725 patients, RE-LY: 18,113 patients). Additionally, Gaubert et al recently investigated the occurrence of ischemic endpoints in acute coronary syndrome (ACS) patients with dabigatran versus VKA medication. In this real-world data as well, it could be shown that dabigatran was associated with an increased thrombotic risk shown by a higher incidence of major adverse cardiovascular events. ${ }^{24}$

However, a recent network analysis did not reveal differences in ischemic outcome of major adverse cardiovascular events comparing different regimen with oral anticoagulants and antiplatelet therapy. ${ }^{25}$ Furthermore, a recent observational study ${ }^{26}$ and a meta-analysis merging observational studies and RCTs did not find a difference in risk of MI. ${ }^{27}$ However, limitations of observational studies such as patient selection, confounders, unknown internationalized normalized ratios in VKA patients, socioeconomic and health care access differences, etc. may have biased the results. Moreover, in the study that merged observational studies and RCTs, ${ }^{27}$ differences between observational studies and RCTs were striking.

A second line of evidence comes from translational and experimental studies ( $\boldsymbol{-}$ Table $\mathbf{1}$ ) that aimed to dissect the underlying mechanism of an increased rate of ischemic events under dabigatran. Olivier et al investigated platelet reactivity in patients on chronic dabigatran treatment. The authors revealed that dabigatran therapy was associated with an increased thrombin receptor-activating peptides (TRAPs)-induced platelet aggregation in a dose-dependent manner. ${ }^{28}$ Interestingly, this effect was not present in patients with additional antiplatelet therapy as shown in a follow-up study of the same group. ${ }^{29}$ Moreover, we recently conducted flow chamber experiments and revealed enhanced platelet adhesion and thrombus formation on human atherosclerotic plaque material in dabigatran-treated patients and could confirm an increased reactivity. ${ }^{30}$ This effect depended on augmented GPIb $\alpha$ signaling, downstream of von Willebrand factor (vWF) binding. Using site-specific blocking antibody or mice deficient in the extracellular domain of GPIb $\alpha$, we could show that an altered thrombin GPIb $\alpha$ interaction is responsible for the prothrombotic ef- fect. ${ }^{30}$ In contrast, a recent analysis conducted by Trabold et al did not observe increased vWF/ristocetin-induced platelet aggregation. ${ }^{31}$ To discuss potential reasons of the discrepant results, it is crucial to appreciate the different experimental setups used in either study. Trabold et al investigated platelets and platelet-rich plasma from healthy volunteers spiked with dabigatran and other divalent thrombin inhibitors, while our group used whole blood from patients under chronic therapy. In the chronic setting, we observed increased level of catalytic inactive thrombin that may favor the formation of thrombin dabigatran complexes. Beyond this noncanonical chronic effect, we and others also observed alteration of platelet function after single-dose treatment. By conducting time series analysis in AF patients with new-onset dabigatran medication, we found an increase in platelet reactivity upon TRAP treatment following a single-dose treatment. There was no influence on aggregation induced by other agonists like adenosine diphosphate (ADP), collagen, or arachidonic acid, respectively. ${ }^{32}$

Thrombin mediates cleavage of its receptor, platelet PAR, from the platelet surface. ${ }^{33}$ Chen et al revealed in first in vitro analyses that dabigatran attenuates thrombin-induced PAR-1 activation, internalization, and cleavage dose-dependently. ${ }^{34}$ In accordance, PAR-1 surface expression increased again by prolonged incubation with inactivated thrombin. ${ }^{34}$ In addition, we could show that in vivo inhibition of thrombin by dabigatran led to increased surface expression of PAR1 and PAR- 4 on platelets measured by flow cytometry. ${ }^{32}$ In an animal model of diabetes, it could furthermore be shown that long-term dabigatran treatment enhances PAR-4 expression. ${ }^{35}$ Moreover, atherosclerosis-related mechanisms and occurrence of coronary lipid deposits could be revealed as further nondirect effects of dabigatran that might explain the enhanced risk for MI as well. ${ }^{35}$

However, other studies did not find increased platelet reactivity by dabigatran. Zemer-Wassercug et al measured platelet aggregation by multiple electrode aggregometry (MEA) in 17 patients and did not show a significant increase of platelet reactivity by dabigatran. ${ }^{36}$ However, most patients were on additional antiplatelet medication potentially repealing prothrombotic effects. ${ }^{30}$ This goes in line with results of Franchi et al and data from our group. Franchi et al investigated platelet reactivity in presence of dabigatran and dual antiplatelet medication. No alterations of platelet reactivity measured by light transmission aggregometry (LTA) and MEA were detected either. ${ }^{37}$ In vitro data from our studies also found, that addition of aspirin abrogated augmented platelet adhesion and thrombus formation under flow conditions in blood from dabigatran-treated patients. ${ }^{30}$

Taken together, dabigatran was shown to increase the rate of MI in RCTs as well as in real-world data. Mechanistically, dabigatran shows some prothrombotic effect by enhancing PAR expression and augmenting GPIb $\alpha$ signaling predominantly under flow conditions. These translational findings might contribute to the increased rate of MI in dabigatrantreated patients. In this context, the influence of antiplatelet medication remains to be insufficiently understood and requires further investigation. 


\section{Factor Xa Inhibitors}

In contrast to FIla inhibition, no increased MI rates were seen in clinical studies investigating FXa inhibitors. Rivaroxaban and apixaban showed a trend toward a reduced incidence of $\mathrm{MI}$ in their first landmark trials. ${ }^{3,4}$ In AF patients post-PCI (PIONEER/AUGUSTUS), again a numerical reduction of MI was found ${ }^{11,12}$ compared with triple therapy with VKA. However, so far it remains unclear whether this trend holds true for all FXa inhibitors in the presence or absence of antiplatelet therapy, or whether substance-specific effects exist. In edoxaban-treated patients, full dose edoxaban medication in ENAGE-AF was associated with a small reduction of MI. ${ }^{6}$ In contrast, ENTRUST enrolled patients undergoing PCI with concomitant antiplatelet therapy; however, edoxaban-treated patients did not show a reduced rate of MI as compared with VKA therapy. ${ }^{38}$ Of note, while discussing these nonsignificant numerical differences of MI frequencies, it has to be considered that none of the NOAC-PCI trials was sufficiently powered to detect differences in ischemic events. Hence, large-scale clinical trials are urgently needed, given the increasing portion of patients treated with NOAC-based dual antithrombotic regimes.

Beside stroke prevention in AF patients and treatment of deep vein thrombosis/pulmonary embolism, a novel concept of low-dose anticoagulation on top of antiplatelet therapy entered the field of antithrombotic regimes. Vascular dose FXa inhibition with rivaroxaban ( $2.5 \mathrm{mg}$ twice daily) was initially investigated in a high-risk cohort of patients presenting with ACS without AF. ATLAS ACS-2-TIMI 51 revealed a reduction of $\mathrm{MI}$ and stroke by vascular dose rivaroxaban on top of dual antiplatelet therapy with aspirin and clopidogrel. ${ }^{39}$ Moreover, the COMPASS trial showed that vascular dose rivaroxaban on top to aspirin improved cardiovascular outcome in patients with stable CAD and peripheral artery disease patients. ${ }^{40,41}$

The use of vascular dose rivaroxaban might also be an alternative to established antiplatelet regimes given the varying pharmacodynamic responses toward antiplatelet medication between individuals. ${ }^{42-45}$ However, a balanced clinical decision making is required before initiation of such antithrombotic regime, considering the increased risk for major bleedings.

Although beyond the focus of this review, some rather unexpected results came from a clinical study investigating the optimal antithrombotic regimen in patients with transcatheter aortic valve implantation (TAVI). The Galileo trial recently investigated FXa inhibition by rivaroxaban, in a reduced dose of $10 \mathrm{mg}$ once daily, on top of aspirin in TAVI patients without AF. ${ }^{46}$ Surprisingly the risk of death or thromboembolic complications was higher compared with the standard antiplatelet-based therapy with clopidogrel, leading to a premature termination of this trial. ${ }^{46}$ Interestingly, subclinical leaflet-motion, as potential surrogate marker for thrombotic valve alteration, was reduced under rivaroxaban as shown in an accompanying imaging study. ${ }^{47}$ Similar findings were made in an earlier animal study that suggested that rivaroxaban might be superior to standard therapy after mechanical valve surgery in terms of valve thrombus and platelet deposition. ${ }^{48}$ Unexpected results came also from the Re-Align study, that aimed to investigate dabigatran in patients after mechanical heart valve surgery. Increased rates of thromboembolic and bleeding complications compared with VKA regimen were observed. ${ }^{49}$ Further studies like ATLANTIS and ENVISAGE-AF trials are ongoing, investigating apixaban and edoxaban in patients with AF and TAVI. ${ }^{50}$ Thus, the type of NOAC and dose regimen seems to be crucial. ${ }^{51}$ None the less in patients with bioprosthetic valves and AF, a full-dose NOAC treatment seems to be as efficient and safe as VKA. ${ }^{52}$

Summarizing the clinical available data, it is suggested that FXa inhibition reduces ischemic events in the different scenarios of atherothrombosis. Triggered by these clinical observations, several in vitro studies investigated the effects of FXa inhibition on platelet activation and coagulation. Perzborn et al were able to show that rivaroxaban reduced tissue factor-induced thrombin formation and platelet aggregation. ${ }^{53}$ Another group observed the same inhibitory effect on thrombin generation and subsequent platelet aggregation for dabigatran and rivaroxaban underscoring the conventional-canonical-efficiency of NOACs to inhibit coagulation and thrombin-driven platelet activation. ${ }^{54}$

As shown before for dabigatran, some experimental and translational studies revealed noncanonical effects on platelet function by FXa inhibitors ( - Table 1 ). Nehaj et al demonstrated that PAR-1-mediated platelet aggregation was reduced in AF patients 2 hours after FXa intake. ${ }^{55}$ Given that TRAP-6 activates platelets though PAR-1 independently of thrombin generation, this data suggested a noncanonical effect. Along this line, we recently described a novel antiplatelet effect of rivaroxaban ${ }^{56}$ by performing time series as well as a cross-sectional analysis in patients treated with FXa inhibitors for stroke prevention under $\mathrm{AF}^{56}$ Rivaroxaban reduced ADP, collagen, TRAP, and plaque material-induced platelet aggregation in whole blood and platelet-rich plasma independently from thrombin. However, these antiplatelet effects required the presence of plasma components ${ }^{56}$ to enable FXa de novo formation and subsequently FXa inhibition by rivaroxaban. Furthermore, rivaroxaban treatment attenuated thrombus formation under arterial flow conditions and altered thrombus composition with reduced fibrinogen content on human atherosclerotic plaque material. As underlying mechanism, we could reveal that FXa acts as direct platelet agonist by activating PAR-1 signaling, triggering phospholipase $\mathrm{C}$ and PI3K activation as key signaling events during platelet activation. As suggested by other studies before, we found a similar effect for apixaban suggesting a FXa group antiplatelet effect. ${ }^{56}$

Additional evidence for noncanonical FXa effects comes from an earlier study by Al-Tamimi et al. They showed that FXa inhibitors attenuate platelet collagen receptor GPVI shedding, thereby reducing soluble GPVI concentrations. ${ }^{57}$ GPVI known as platelet main collagen receptor, ${ }^{58,59}$ mediates platelet activation at the site of atherosclerotic plaque rupture that come along with the exposure of highly thrombogenic subendothelial matrix proteins. At sites of thrombus 
formation, GPVI signaling capacity is regulated by receptor shedding to prevent excessive platelet activation and thrombus formation. ${ }^{60}$ While several metalloproteinase were identified to cleave GPVI and generate a soluble ectodomain, a coagulation-induced FXa-driven, thrombin-independent shedding mechanism was described. ${ }^{57}$ Against this background, Pignatelli et $\mathrm{al}^{61}$ found reduced, soluble GPVI levels, as marker for reduced platelet activation in patients under FXa inhibition. Whether this mechanism will indeed reduce platelet activation in vivo needs to be proven. Further evidence for noncanonical FXa effects, comes from a recent study using in silico docking modeling. This study proposed a direct interaction of rivaroxaban with GPVI. Thereby rivaroxaban inhibits thromboxane biosynthesis and oxidative stress generation by Nox-2 following GPVI activation by convulxin. ${ }^{63}$ Importantly, in all three scenarios FXa-mediated antiplatelet effects were independent from catalytic active thrombin.
None the less, some other studies did not find any effect of FXa treatment on platelet aggregation in either whole blood or platelet-rich plasma. Zemer-Wassercug et al investigated rivaroxaban-antiplatelet effects but could not reveal any antiplatelet effects as measured by MEA, P-selectin expression, platelet deposition, and RANTES levels. ${ }^{36}$ However, the interpretation of this study is limited as a significant percentage of patients was on concomitant aspirin therapy. Furthermore, Steppich et al conducted a time series analysis in 38 apixaban- or rivaroxaban-treated patients. Thrombin generation, aggregation measured by MEA, and expression of thrombospondin, $\beta$-thromboglobulin, and soluble P-selectin were investigated. Whole blood aggregation did not change during the time course. However, thrombin generation as well as expression of thrombospondin were reduced. ${ }^{62}$ Bánovčin et al evaluated platelet aggregation measured by LTA in 9 rivaroxaban- and 12 apixaban-treated AF patients in a time series analysis to compare responses at baseline peak

\section{Factor Xa inhibitors}

\section{Oral thrombin inhibitors}

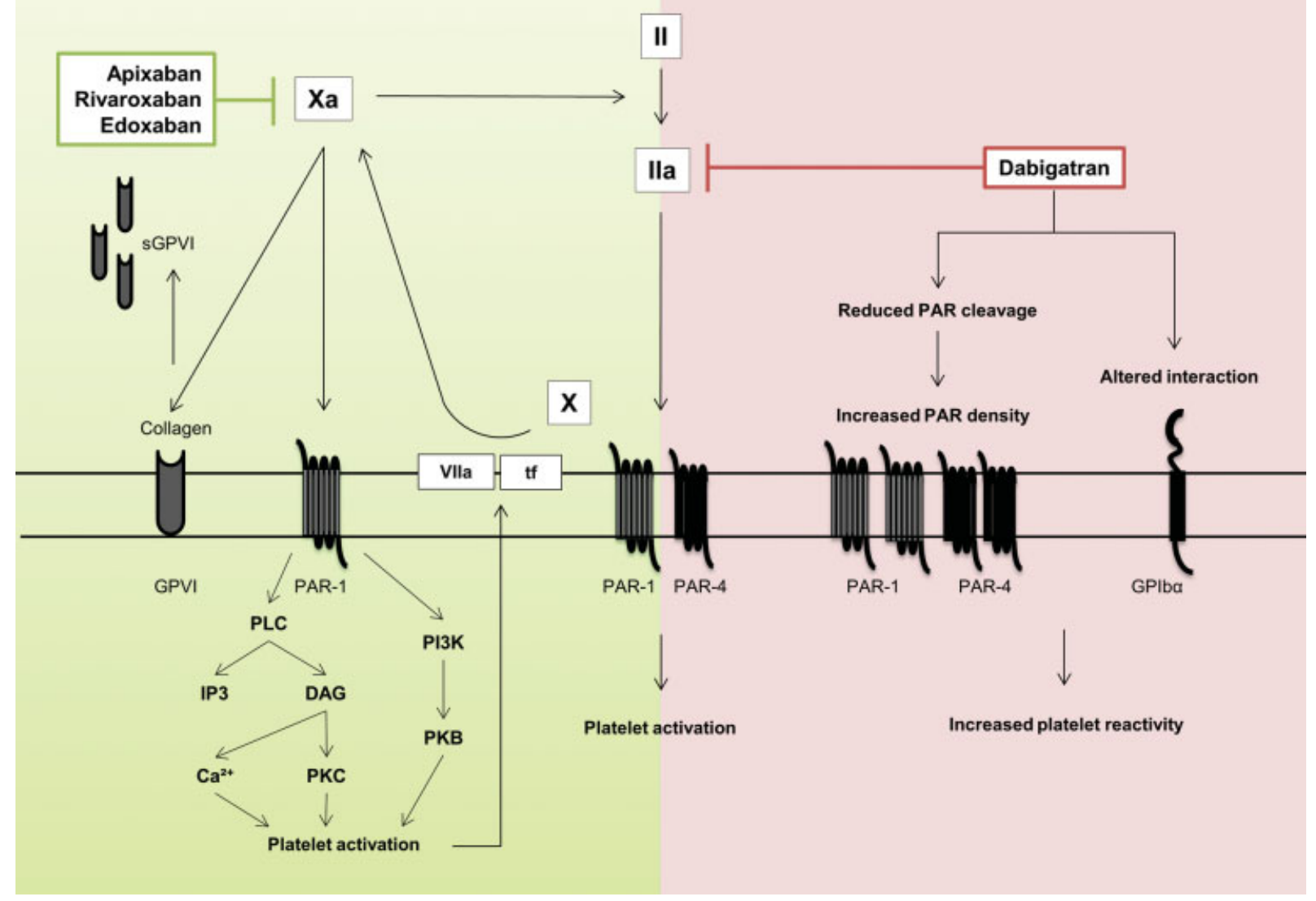

Fig. 3 Noncanonical mechanisms of nonvitamin K oral anticoagulants (NOACs) on platelet function. Factor Xa (FXa) inhibitors trigger antiplatelet effects by reducing FXa-mediated platelet activation of protease-activated receptor-1 (PAR-1). PAR-1 cleavage by FXa activates platelets via the phospholipase C (PLC) and phosphoinositide 3-kinase (PI3K) pathways. In the presence of plasma, platelet activation (e.g., during aggregation) by various agonists induces FXa de novo formation by augmenting tissue factor (tf) exposure, finally triggering cleavage of FX. Another mechanism suggests that FXa inhibitors can directly interact with platelet glycoprotein (GP) VI thereby reducing NOX-2-mediated reactive oxygen species (ROS) production and platelet activation. Furthermore, FXa was shown to proteolytically cleave GPVI, yielding a soluble GPVI ectodomain (sGPVI). Reduced plasma levels of sGPVI in the presence of FXa inhibitors reflect reduced systemic platelet activation. Oral thrombin inhibitor treatment induces prothrombotic effects on platelet function by reducing cleavage of surface expressed PAR receptors, yielding augmented PAR receptors surface expression level. Moreover, dabigatran leads to an altered thrombin-GPIba interaction, triggering increased platelet reactivity and thrombus formation downstream of von Willebrand factor (vWF) binding. 
Table 1 Summary of experimental study results and main outcome variables

\begin{tabular}{|c|c|c|c|c|c|c|c|}
\hline & Ref. & Mode & Dose & Study object & Duration & Assay & Outcome \\
\hline \multirow[t]{20}{*}{ Human } & 28 & $\mathrm{ts}+\mathrm{cs}$ & $\begin{array}{l}\text { DABI } 75,110 \text { or } 150 \mathrm{mg} 2 \times / \mathrm{d} \text {; } \\
\text { RIVA } 10,15 \text { or } 20 \mathrm{mg} 1 \times / \mathrm{d}\end{array}$ & Patients (AF) & Chronic & MEA (TRAP) & $\begin{array}{l}\text { Increased aggregation under } \\
\text { DABI (dose-dependent) }\end{array}$ \\
\hline & 32 & ts & DABI 110 or $150 \mathrm{mg}$ & Patients (AF) & $\begin{array}{l}\text { Single } \\
\text { dose }\end{array}$ & LTA (TRAP, ADP, collagen, AA) & $\begin{array}{l}\text { Increase in platelet reactivity } \\
\text { only upon TRAP }\end{array}$ \\
\hline & 36 & ts & $\begin{array}{l}\text { DABI } 110 \text { or } 150 \mathrm{mg} 2 \times / \mathrm{d} \text { or } \\
\text { RIVA } 15 \text { or } 20 \mathrm{mg} 1 \times / \mathrm{d}\end{array}$ & Patients (AF) & Chronic & $\begin{array}{l}\text { MEA (+Impact-R shear-induced } \\
\text { platelet deposition, P-selectin, } \\
\text { plasma RANTES levels) }\end{array}$ & $\begin{array}{l}\text { No increase in platelet reactiv- } \\
\text { ity under } D A B I\end{array}$ \\
\hline & 37 & ts & DABI $150 \mathrm{mg} 2 \times / \mathrm{d}$ & $\begin{array}{l}\text { Patients } \\
\text { (CAD) }\end{array}$ & Chronic & $\mathrm{LTA}+\mathrm{MEA}$ & $\begin{array}{l}\text { No change in platelet reactivity } \\
\text { under DABI + DAPT }\end{array}$ \\
\hline & 30 & cs & $\begin{array}{l}\text { DABI } 150 \mathrm{mg} 2 \times / \mathrm{d} \text { or blood } \\
\text { from DABI }(150 \mathrm{mg} 2 \times / \mathrm{d}) \\
\text { patients spiked with } 1 \mathrm{mM} \text { ASA }\end{array}$ & $\begin{array}{l}\text { Patients } \\
(\mathrm{AF})+\text { healthy }\end{array}$ & Chronic & Flow chamber + MEA & $\begin{array}{l}\text { Enhanced platelet adhesion } \\
\text { under DABI, which can be ab- } \\
\text { rogated by ASA }\end{array}$ \\
\hline & 55 & ts & $\begin{array}{l}\text { RIVA } 15 \mathrm{mg} 1 \times / \mathrm{d} \text { or APIXA } 2,5 \text {, } \\
\text { or } 5 \mathrm{mg} 2 \times / \mathrm{d}\end{array}$ & Patients (AF) & Chronic & LTA (TRAP) & $\begin{array}{l}\text { Reduced aggregation } 2 \mathrm{~h} \text { after } \\
\text { RIVA or APIXA intake }\end{array}$ \\
\hline & 61 & cs & $\begin{array}{l}\text { APIXA } 10 \mathrm{mg} / \mathrm{d} \text { or RIVA } \\
20 \mathrm{mg} / \mathrm{d}\end{array}$ & Patients (AF) & Chronic & Enzyme immunoassay & $\begin{array}{l}\text { Reduced soluble GPVI levels } \\
\text { under FXa inhibition }\end{array}$ \\
\hline & 62 & ts & $\begin{array}{l}\text { APIXA }(5 \mathrm{mg} 2 \times / \mathrm{d}) \text { or RIVA } \\
(20 \mathrm{mg} 1 \times / \mathrm{d})\end{array}$ & Patients (AF) & Chronic & $\begin{array}{l}\text { Thrombin generation, MEA, ex- } \\
\text { pression of thrombospondin, P- } \\
\text { selectin }\end{array}$ & $\begin{array}{l}\text { No effect on platelet reactivity } \\
\text { under RIVA or APIXA }\end{array}$ \\
\hline & 63 & ts & APIXA or RIVA & Patients (AF) & Chronic & LTA (ADP, epinephrine, collagen) & $\begin{array}{l}\text { No change in aggregation in- } \\
\text { dependent of plasma levels }\end{array}$ \\
\hline & 56 & ts $+\mathrm{cs}$ & RIVA $20 \mathrm{mg}$ & $\begin{array}{l}\text { Patients } \\
(\mathrm{AF})+\text { healthy }\end{array}$ & $\begin{array}{l}\text { Chronic }+ \\
\text { single } \\
\text { dose }\end{array}$ & $\begin{array}{l}\text { LTA, MEA, flow chamber on human } \\
\text { atherosclerotic plaque }\end{array}$ & $\begin{array}{l}\text { RIVA reduces arterial throm- } \\
\text { bosis by inhibition of FXa-driv- } \\
\text { en platelet activation }\end{array}$ \\
\hline & 29 & ts & $\begin{array}{l}\text { DABI } 75,110 \text {, or } 150 \mathrm{mg} 2 \times / \mathrm{d} \text {, } \\
\text { RIVA } 10,15 \text {, or } 20 \mathrm{mg} 1 \times / \mathrm{d} \text {; } \\
+/- \text { ASA or clopidogrel }\end{array}$ & $\begin{array}{l}\text { Patients } \\
(\mathrm{AF}+\mathrm{VTE})\end{array}$ & Chronic & MEA (ADP and AA) & $\begin{array}{l}\text { No impact of NOACs on anti- } \\
\text { platelet effects of } \\
\text { ASA + clopidogrel }\end{array}$ \\
\hline & 64 & cs & RIVA (dosing unknown) & $\begin{array}{l}\text { Patients } \\
\text { (VTE + AF) }\end{array}$ & Chronic & sCD40L, PFA4, TXA2 & $\begin{array}{l}\text { Similar levels of } \\
\text { sCD } 40 \mathrm{~L}+\text { PFA4, but increased } \\
\text { peak TXA2 levels in RIVA } \\
\text { patients }\end{array}$ \\
\hline & 65 & ts & RIVA $20 \mathrm{mg} 1 \times / \mathrm{d}$ & $\begin{array}{l}\text { Patients } \\
\text { (VTE) }\end{array}$ & Chronic & LTA + P-selectin & $\begin{array}{l}\text { No intraindividual effects on } \\
\text { platelet reactivity of RIVA at } \\
\text { peak and trough plasma level }\end{array}$ \\
\hline & 31 & Ex vivo & $\begin{array}{l}\text { Platelets + PRP spiked with } \\
\text { DABI }(500 \mathrm{nM}) \text { or lepirudin } \\
(200 \mu \mathrm{g} / \mathrm{mL})\end{array}$ & Healthy & $\begin{array}{l}\text { Single } \\
\text { dose }\end{array}$ & LTA (ristocetin) & $\begin{array}{l}\text { No increase in aggregation un- } \\
\text { der DABI or lepirudin }\end{array}$ \\
\hline & 53 & Ex vivo & $\begin{array}{l}\text { PRP spiked with RIVA ( } 15 \text { or } \\
30 \mathrm{ng} / \mathrm{mL} \text { ), ticagrelor ( } 1 \text { or } 3 \\
\mu \mathrm{g} / \mathrm{mL} \text { ), or both }\end{array}$ & Healthy & $\begin{array}{l}\text { Single } \\
\text { dose }\end{array}$ & LTA (TF) & $\begin{array}{l}\text { RIVA reduced platelet } \\
\text { aggregation }\end{array}$ \\
\hline & 54 & Ex vivo & $\begin{array}{l}\text { Citrated blood spiked with } \\
\text { DABI }(25-800 \mathrm{nM} / \mathrm{L}) \text { or RIVA } \\
(25-800 \mathrm{nM} / \mathrm{L})\end{array}$ & Healthy & $\begin{array}{l}\text { Single } \\
\text { dose }\end{array}$ & $\begin{array}{l}\text { SINNOWA, endogenous thrombin } \\
\text { potential }\end{array}$ & $\begin{array}{l}\text { RIVA + DABI reduce thrombin } \\
\text { generation + platelet } \\
\text { aggregation }\end{array}$ \\
\hline & 57 & Ex vivo & PRP spiked with RIVA $1 \mu \mathrm{g} / \mathrm{mL}$ & Healthy & $\begin{array}{l}\text { Single } \\
\text { dose }\end{array}$ & $\begin{array}{l}\text { Coagulation-induced sGPVI gener- } \\
\text { ation measured by ELISA }\end{array}$ & $\begin{array}{l}\text { FXa inhibitors attenuate GPVI } \\
\text { shedding and reduce soluble } \\
\text { GPVI concentrations }\end{array}$ \\
\hline & 68 & Ex vivo & $\begin{array}{l}\text { Platelets spiked with RIVA } \\
15-60 \mathrm{ng} / \mathrm{mL}\end{array}$ & Healthy & $\begin{array}{l}\text { Single } \\
\text { dose }\end{array}$ & Docking simulation analysis & $\begin{array}{l}\text { Direct interaction of RIVA with } \\
\text { GPVI }\end{array}$ \\
\hline & 66 & ts & RIVA $10 \mathrm{mg}$ & Healthy & $\begin{array}{l}\text { Single } \\
\text { dose }\end{array}$ & MEA (AA, TRAP, ristocetin, ADP) & $\begin{array}{l}\text { No influence of Xa inhibition on } \\
\text { platelet aggregation }\end{array}$ \\
\hline & 34 & Ex vivo & $\begin{array}{l}\text { Thrombin preincubated with } \\
\text { DABI }(0-30 \mathrm{nM})\end{array}$ & $\begin{array}{l}\text { Human } \\
\text { thrombin }\end{array}$ & $\begin{array}{l}\text { Single } \\
\text { dose }\end{array}$ & PAR-1 cleavage analysis; FACS & $\begin{array}{l}\text { DABI attenuates thrombin-in- } \\
\text { duced PAR-1 activation stabi- } \\
\text { lizing PAR-1 surface expression }\end{array}$ \\
\hline \multirow[t]{3}{*}{ Animal } & 30 & cs & $\mathrm{DABI} 37.5 \mathrm{mg} / \mathrm{kg}$ bw & Mouse & $\begin{array}{l}\text { Single } \\
\text { dose }\end{array}$ & Wire injury model & $\begin{array}{l}\text { Prothromogenic, increased } \\
\text { thrombus stability under DABI }\end{array}$ \\
\hline & 35 & CS & DABI 1 or $0.3 \mathrm{mg} / \mathrm{g}$ bw & Rat & Chronic & Immunohistochemistry & $\begin{array}{l}\text { Enhanced PAR-4 expression } \\
\text { under DABI }\end{array}$ \\
\hline & 48 & CS & RIVA $2 \mathrm{mg} / \mathrm{kg} 2 \times / \mathrm{d}$ & Pig & Chronic & $\begin{array}{l}\text { Model of mechanical aortic valve } \\
\text { prosthesis }\end{array}$ & $\begin{array}{l}\text { RIVA was more effective than } \\
\text { enoxaparin for short-term } \\
\text { thromboprophylaxis }\end{array}$ \\
\hline
\end{tabular}

Abbreviations: AA, arachidonic acid; ADP, adenosine diphosphate; AF, atrial fibrillation; APIXA, apixaban; ASA, acetylsalicylic acid; bw, body weight; CAD, coronary artery disease; cs, cross-sectional; DABI, dabigatran; ELISA, enzyme-linked immunosorbent assay; FACS, fluorescence-activated cell sorting; LTA, light transmission aggregometry; MEA, multiple electrode aggregometry; PAR-1, protease-activated receptor-1; PFA4, platelet factor 4; PRP, platelet-rich plasma; RIVA, rivaroxaban; sCD40L, soluble CD40 ligand; SGPVI, soluble glycoprotein VI; TF, tissue factor; TRAP, thrombin receptor activating protein; ts, time series; TXA2, thromboxane A2; VTE, venous thromboembolism.

Note: Chronic $>7$ days and single dose $<7$ days. 
and trough plasma level but did not show a significant alteration of platelet responses. ${ }^{63}$

In the context of recurrent venous thromboembolism (VTE), a different disease entity requiring long-term anticoagulation, a small study (total 8 patients: 7 recurrent VTE, $1 \mathrm{AF}$ ) analyzed the impact of rivaroxaban on platelet activation markers. While soluble CD40 ligand and platelet factor 4 did not differ compared with healthy controls, peak thromboxane $\mathrm{A} 2$ levels in patients with rivaroxaban medication ${ }^{64}$ were increased. Though the underlying molecular mechanism remains elusive, the authors postulate a prothrombogenic effect of rivaroxaban. Another recent study performed time series analysis of platelet function in VTE patients on rivaroxaban and after cessation of anticoagulation. Schultz et al did not find any significant intraindividual effects on platelet reactivity (i.e., LTA aggregation and P-selectin) of rivaroxaban peak and trough plasma level. However, the authors revealed a trend toward a reduced P-selectin expression under rivaroxaban treatment. ${ }^{65} \mathrm{~A}$ study by Schoergenhofer et al analyzed diurnal variation in platelet reactivity by MEA following 3 days of intermediate dose $(10 \mathrm{mg})$ rivaroxaban treatment, but did not find any impact on platelet reactivity. ${ }^{66}$

\section{Limitations}

While reviewing the current knowledge we found partially contradicting reports regarding the effects of FIIa and FXa inhibitors on platelet function in the context of atherothrombosis. Although the origin of these discrepancies remained in parts elusive, some aspects have to be considered while interpreting the data. An important potential confounder is given by comparing data generated from patients' samples with samples isolated from healthy controls that were spiked with active NOAC in vitro. In particular, as NOAC effects might be more prominent in patient samples what might exhibit altered platelet baseline activation due to diseasespecific effects. Patient samples isolated from anticoagulated AF patients show alterations of the coagulation system and platelet parameters. ${ }^{67}$ On the other hand, patient samples often show a broad variability, due to various known and unknown interindividual confounders, that are difficult to compensate for in small-scale translational studies. Thus, time series analysis should be preferred over cross-sectional analysis. Next, considering the (expected) rather mild effects of NOAC on platelet function it seems crucial to use the same experimental setup and conditions (i.e., anticoagulants used, sample transport time, centrifugation steps, platelet concentration, etc.). Hence, standardized, multicenter translational studies may help to improve the reproducibility and generalizability of data.

\section{Conclusion}

In this review, we focused on noncanonical effects of oral thrombin and FXa inhibitors in platelet activation and arterial thrombosis (-Fig. 3). Translational studies identified different prothrombogenic noncanonical effects under FIla inhibitor treatment, yielding increased platelet reactivity. In contrast, different noncanonical mechanisms resulting in reduced platelet reactivity and thrombus formation in patients treated with FXa inhibitors were described. Still, these noncanonical effects are complex and not completely understood and it seems likely that additional so far unknown mechanisms exist. Hence, an optimal individualized NOAC therapy requires further standardized translational analysis and a careful definition of secondary and safety endpoints in large-scale clinical trials.

\section{Authors' Contributions}

A.P., L.D., and T.P. wrote the initial draft of the manuscript and later finalized the manuscript. M.K. gave valuable input to the manuscript. G.W., M.T., M.O. T.Z., and T.H. revised the manuscript.

\section{Funding}

This work was supported by the Forschungskommission of the Medical Faculty of the Heinrich Heine University [No. 18-2019 to A.P.; No. 2019-29 to L.D., No. 2018-32 to G.W.] and by the German Research Foundation (PO 2247/ 2-1 and SFB1116 to A.P and PE2704/2-1 to T.P..), by Deutsche Herzstiftung (F/04/19 shared with Dr. Lüsebrink).

Conflict of Interest

None declared.

\section{References}

1 Kirchhof P, Benussi S, Kotecha D, et al; ESC Scientific Document Group. 2016 ESC Guidelines for the management of atrial fibrillation developed in collaboration with EACTS. Eur Heart J 2016;37 (38):2893-2962

2 Konstantinides SV, Meyer G, Becattini C, et al; The Task Force for the diagnosis and management of acute pulmonary embolism of the European Society of Cardiology (ESC). 2019 ESC Guidelines for the diagnosis and management of acute pulmonary embolism developed in collaboration with the European Respiratory Society (ERS): the Task Force for the diagnosis and management of acute pulmonary embolism of the European Society of Cardiology (ESC). Eur Respir J 2019;54(03):54

3 Patel MR, Mahaffey KW, Garg J, et al; ROCKET AF Investigators. Rivaroxaban versus warfarin in nonvalvular atrial fibrillation. N Engl J Med 2011;365(10):883-891

4 Granger CB, Alexander JH, McMurray JJ, et al; ARISTOTLE Committees and Investigators. Apixaban versus warfarin in patients with atrial fibrillation. N Engl J Med 2011;365(11):981-992

5 Connolly SJ, Ezekowitz MD, Yusuf S, et al; RE-LY Steering Committee and Investigators. Dabigatran versus warfarin in patients with atrial fibrillation. N Engl J Med 2009;361(12):1139-1151

6 Giugliano RP, Ruff CT, Braunwald E, et al; ENGAGE AF-TIMI 48 Investigators. Edoxaban versus warfarin in patients with atrial fibrillation. N Engl J Med 2013;369(22):2093-2104

7 Olimpieri PP, Di Lenarda A, Mammarella F, et al. Non-vitamin K antagonist oral anticoagulation agents in patients with atrial fibrillation: insights from Italian monitoring registries. Int J Cardiol Heart Vasc 2020;26:100465

8 Coleman CI, Peacock WF, Bunz TJ, Alberts MJ. Effectiveness and safety of apixaban, dabigatran, and rivaroxaban versus warfarin in patients with nonvalvular atrial fibrillation and previous stroke or transient ischemic attack. Stroke 2017;48(08):2142-2149 
9 Cannon CP, Bhatt DL, Oldgren J, et al; RE-DUAL PCI Steering Committee and Investigators. Dual antithrombotic therapy with dabigatran after PCI in atrial fibrillation. N Engl J Med 2017;377 (16):1513-1524

10 Artang R, Rome E, Nielsen JD, Vidaillet HJ. Meta-analysis of randomized controlled trials on risk of myocardial infarction from the use of oral direct thrombin inhibitors. Am J Cardiol 2013;112(12):1973-1979

11 Gibson CM, Mehran R, Bode C, et al. Prevention of bleeding in patients with atrial fibrillation undergoing PCI. N Engl J Med 2016;375(25):2423-2434

12 Lopes RD, Heizer G, Aronson R, et al; AUGUSTUS Investigators. Antithrombotic therapy after acute coronary syndrome or $\mathrm{PCI}$ in atrial fibrillation. N Engl J Med 2019;380(16):1509-1524

13 Ten Cate H, Hemker HC. Thrombin generation and atherothrombosis: what does the evidence indicate? J Am Heart Assoc 2016;5 (08):5

14 Chan NC, Weitz JI. Antithrombotic agents. Circ Res 2019;124(03): 426-436

15 Niewiarowski S, Thomas DP. Platelet aggregation by ADP and thrombin. Nature 1966;212(5070):1544-1547

16 Mangiacapra F, Colaiori I, Ricottini E, et al. Impact of platelet reactivity on 5-year clinical outcomes following percutaneous coronary intervention: a landmark analysis. J Thromb Thrombolysis 2018;45(04):496-503

17 Dannenberg L, Metzen D, Zako S, et al. Enhanced platelet reactivity under aspirin medication and major adverse cardiac and cerebrovascular events in patients with coronary artery disease. Pharmacology 2020;105(1-2):118-122

18 Dubois C, Steiner B, Kieffer N, Reigner SC. Thrombin binding to GPIbalpha induces platelet aggregation and fibrin clot retraction supported by resting alphallbbeta3 interaction with polymerized fibrin. Thromb Haemost 2003;89(05):853-865

19 Esmon CT. Targeting factor Xa and thrombin: impact on coagulation and beyond. Thromb Haemost 2014;111(04):625-633

20 Spronk HM, de Jong AM, Crijns HJ, Schotten U, Van Gelder IC, Ten Cate H. Pleiotropic effects of factor Xa and thrombin: what to expect from novel anticoagulants. Cardiovasc Res 2014;101(03): 344-351

21 Jackson SP. Arterial thrombosis-insidious, unpredictable and deadly. Nat Med 2011;17(11):1423-1436

22 Connolly SJ, Ezekowitz MD, Yusuf S, Reilly PA, Wallentin LRandomized Evaluation of Long-Term Anticoagulation Therapy Investigators. Newly identified events in the RE-LY trial. N Engl J Med 2010;363(19):1875-1876

23 Hohnloser SH, Oldgren J, Yang S, et al. Myocardial ischemic events in patients with atrial fibrillation treated with dabigatran or warfarin in the RE-LY (Randomized Evaluation of Long-Term Anticoagulation Therapy) trial. Circulation 2012;125(05): 669-676

24 Gaubert M, Resseguier N, Laine M, Bonello L, Camoin-Jau L, Paganelli F. Dabigatran versus vitamin k antagonist: an observational across-cohort comparison in acute coronary syndrome patients with atrial fibrillation. J Thromb Haemost 2018;16 (03):465-473

25 Kuno T, Ueyama H, Takagi H, et al. Meta-analysis of antithrombotic therapy in patients with atrial fibrillation undergoing percutaneous coronary intervention. Am J Cardiol 2020;125 (04):521-527

26 Lee CJ, Gerds TA, Carlson N, et al. Risk of myocardial infarction in anticoagulated patients with atrial fibrillation. J Am Coll Cardiol 2018;72(01):17-26

27 Wei $\mathrm{AH}, \mathrm{Gu} \mathrm{ZC}$, Zhang $\mathrm{C}$, et al. Increased risk of myocardial infarction with dabigatran etexilate: fact or fiction? A critical meta-analysis of over 580,000 patients from integrating randomized controlled trials and real-world studies. Int J Cardiol 2018; 267:1-7
28 Olivier CB, Weik P, Meyer M, et al. TRAP-induced platelet aggregation is enhanced in cardiovascular patients receiving dabigatran. Thromb Res 2016;138:63-68

29 Olivier CB, Weik P, Meyer M, et al. Dabigatran and rivaroxaban do not affect AA- and ADP-induced platelet aggregation in patients receiving concomitant platelet inhibitors. J Thromb Thrombolysis 2016;42(02):161-166

30 Petzold T, Thienel M, Konrad I, et al. Oral thrombin inhibitor aggravates platelet adhesion and aggregation during arterial thrombosis. Sci Transl Med 2016;8(367):367ra168

31 Trabold K, Makhoul S, Gambaryan S, van Ryn J, Walter U, Jurk K. The direct thrombin inhibitors dabigatran and lepirudin inhibit GPIb $\alpha$-mediated platelet aggregation. Thromb Haemost 2019; 119(06):916-929

32 Achilles A, Mohring A, Dannenberg L, et al. Dabigatran enhances platelet reactivity and platelet thrombin receptor expression in patients with atrial fibrillation. J Thromb Haemost 2017;15(03): 473-476

33 Nieman MT, Schmaier AH. Interaction of thrombin with PAR1 and PAR4 at the thrombin cleavage site. Biochemistry 2007;46(29): 8603-8610

34 Chen B, Soto AG, Coronel LJ, Goss A, van Ryn J, Trejo J. Characterization of thrombin-bound dabigatran effects on protease-activated receptor-1 expression and signaling in vitro. Mol Pharmacol 2015;88(01):95-105

35 Scridon A, Mărginean A, Huțanu A, et al. Vascular proteaseactivated receptor 4 upregulation, increased platelet aggregation, and coronary lipid deposits induced by long-term dabigatran administration - results from a diabetes animal model. J Thromb Haemost 2019;17(03):538-550

36 Zemer-Wassercug N, Haim M, Leshem-Lev D, et al. The effect of dabigatran and rivaroxaban on platelet reactivity and inflammatory markers. J Thromb Thrombolysis 2015;40(03):340-346

37 Franchi F, Rollini F, Cho JR, et al. Effects of dabigatran on the cellular and protein phase of coagulation in patients with coronary artery disease on dual antiplatelet therapy with aspirin and clopidogrel. Results from a prospective, randomised, doubleblind, placebo-controlled study. Thromb Haemost 2016;115 (03):622-631

38 Vranckx P, Valgimigli M, Eckardt L, et al. Edoxaban-based versus vitamin $\mathrm{K}$ antagonist-based antithrombotic regimen after successful coronary stenting in patients with atrial fibrillation (ENTRUST-AF PCI): a randomised, open-label, phase 3b trial. Lancet 2019;394(10206):1335-1343

39 Mega JL, Braunwald E, Wiviott SD, et al; ATLAS ACS 2-TIMI 51 Investigators. Rivaroxaban in patients with a recent acute coronary syndrome. N Engl J Med 2012;366(01):9-19

40 Eikelboom JW, Connolly SJ, Bosch J, et al; COMPASS Investigators. Rivaroxaban with or without aspirin in stable cardiovascular disease. N Engl J Med 2017;377(14):1319-1330

41 Anand SS, Caron F, Eikelboom JW, et al. Major adverse limb events and mortality in patients with peripheral artery disease: the COMPASS trial. J Am Coll Cardiol 2018;71(20):2306-2315

42 Polzin A, Dannenberg L, Sansone R, et al. Antiplatelet effects of aspirin in chronic kidney disease patients. J Thromb Haemost 2016;14(02):375-380

43 Polzin A, Kelm M, Zeus T. Impaired clopidogrel antiplatelet effects and age: young patients at risk. Int J Cardiol 2015;187:216-218

44 Polzin A, Afzal S, Balzer J, Rassaf T, Kelm M, Zeus T. Platelet reactivity in MitraClip patients. Vascul Pharmacol 2016;77:54-59

45 Polzin A, Dannenberg L, Sophia Popp V, Kelm M, Zeus T. Antiplatelet effects of clopidogrel and aspirin after interventional patent foramen ovale/ atrium septum defect closure. Platelets 2016;27(04):317-321

46 Dangas GD, Tijssen JGP, Wöhrle J, et al; GALILEO Investigators. A controlled trial of rivaroxaban after transcatheter aortic-valve replacement. N Engl J Med 2020;382(02):120-129 
47 De Backer O, Dangas GD, Jilaihawi H, et al; GALILEO-4D Investigators. Reduced leaflet motion after transcatheter aortic-valve replacement. N Engl J Med 2020;382(02):130-139

48 Greiten LE, McKellar SH, Rysavy J, Schaff HV. Effectiveness of rivaroxaban for thromboprophylaxis of prosthetic heart valves in a porcine heterotopic valve model. Eur J Cardiothorac Surg 2014; 45(05):914-919

49 Eikelboom JW, Connolly SJ, Brueckmann M, et al; RE-ALIGN Investigators. Dabigatran versus warfarin in patients with mechanical heart valves. N Engl J Med 2013;369(13):1206-1214

50 Van Mieghem NM, Unverdorben M, Valgimigli M, et al. Edoxaban versus standard of care and their effects on clinical outcomes in patients having undergone transcatheter aortic valve implantation in atrial fibrillation-rationale and design of the ENVISAGETAVI AF trial. Am Heart J 2018;205:63-69

51 Aimo A, Giugliano RP, De Caterina R, Non-Vitamin K. Non-vitamin $\mathrm{K}$ antagonist oral anticoagulants for mechanical heart valves: is the door still open? Circulation 2018;138(13):1356-1365

52 Andrade JG, Meseguer E, Didier R, Dussault C, Weitz JI. Nonvitamin $\mathrm{K}$ antagonist oral anticoagulants in atrial fibrillation patients with bioprosthetic valves. Expert Rev Cardiovasc Ther 2018. Doi: 10.1080/14779072.2018.1475229

53 Perzborn E, Heitmeier S, Laux V. Effects of rivaroxaban on platelet activation and platelet-coagulation pathway interaction: in vitro and in vivo studies. J Cardiovasc Pharmacol Ther 2015;20(06): 554-562

54 Wan H, Yang Y, Zhu J, et al. An in-vitro evaluation of direct thrombin inhibitor and factor Xa inhibitor on tissue factorinduced thrombin generation and platelet aggregation: a comparison of dabigatran and rivaroxaban. Blood Coagul Fibrinolysis 2016;27(08):882-885

55 Nehaj F, Sokol J, Ivankova J, et al. First evidence: TRAP-induced platelet aggregation is reduced in patients receiving xabans. Clin Appl Thromb Hemost 2018;24(06):914-919

56 Petzold T, Thienel M, Dannenberg LK, et al. Rivaroxaban reduces arterial thrombosis by inhibition of FXa driven platelet activation via protease activated receptor-1. Circ Res 2020;126(04):486-500
57 Al-Tamimi M, Grigoriadis G, Tran H, et al. Coagulation-induced shedding of platelet glycoprotein VI mediated by factor Xa. Blood 2011;117(14):3912-3920

58 Massberg S, Gawaz M, Grüner S, et al. A crucial role of glycoprotein VI for platelet recruitment to the injured arterial wall in vivo.J Exp Med 2003;197(01):41-49

59 Varga-Szabo D, Pleines I, Nieswandt B. Cell adhesion mechanisms in platelets. Arterioscler Thromb Vasc Biol 2008;28(03):403-412

60 Bender M, Stegner D, Nieswandt B. Model systems for platelet receptor shedding. Platelets 2017;28(04):325-332

61 Pignatelli P, Pastori D, Bartimoccia S, et al. Anti Xa oral anticoagulants inhibit in vivo platelet activation by modulating glycoprotein VI shedding. Pharmacol Res 2016;113(Pt A):484-489

62 Steppich B, Dobler F, Brendel LC, et al. Effect of the FXa inhibitors Rivaroxaban and Apixaban on platelet activation in patients with atrial fibrillation. J Thromb Thrombolysis 2017;43(04):490-497

63 Bánovčin P Jr, Škorňová I, Samoš M, et al. Platelet aggregation in direct oral factor Xa inhibitors-treated patients with atrial fibrillation: a pilot study. J Cardiovasc Pharmacol 2017;70(04): 263-266

64 Murphy PT, Grace S, Glavey S, Quinn J. Rivaroxaban may increase platelet activation in vivo via thromboxane A2. Circ Res 2019;125 (02):e9

65 Schultz NH, Holme PA, Bjørnsen S, Henriksson CE, Sandset PM, Jacobsen EM. The impact of rivaroxaban on primary hemostasis in patients with venous thrombosis. Platelets 2020;31(01):43-47

66 Schoergenhofer C, Schwameis M, Brunner M, et al. Assessing the influence of diurnal variations and selective Xa inhibition on whole blood aggregometry. Scand J Clin Lab Invest 2015;75(06): 531-536

67 Makowski M, Smorag I, Makowska J, et al. Platelet reactivity and mean platelet volume as risk markers of thrombogenesis in atrial fibrillation. Int J Cardiol 2017;235:1-5

68 Cammisotto V, Carnevale R, Nocella C, et al. Nox2-mediated platelet activation by glycoprotein (GP) VI: Effect of rivaroxaban alone and in combination with aspirin. Biochem Pharmacol 2019; 163:111-118 